\title{
NOTES
}

\section{Solvent Effects on the Radical Polymerization of Vinyl Pivalate}

\author{
Ryohei Fukae,* Koichi KawaKami, ${ }^{* *}$ Tohei Yamamoto, ${ }^{* * *}$ \\ Osamu SANGEN, ${ }^{* * *}$ Takeshi KaKo, ${ }^{*}$ and Mikiharu KAMACHI ${ }^{* * * *}$ \\ * Himeji Junior College, Shinzaikehoncho, Himeji 670, Japan \\ ** Nippon Polymer Kogyo Co., Aboshi, Himeji 671-12, Japan \\ *** Himeji Institute of Technology, Shosha, Himeji 671-22, Japan \\ **** Faculty of Science, Osaka University, Toyonaka 560, Japan
}

(Received June 1, 1995)

KEY WORDS Vinyl Pivalate / Radical Polymerization / Solvent Effects / High Molecular Weight / High Syndiotacticity /

In our study on the synthesis of high molecular weight poly(vinyl alcohol) (PVA), we obtained high molecular weight poly(vinyl pivalate) (PVP) which afforded PVA with high syndiotacticity through saponification. ${ }^{1,2}$ The physical properties of PVA are influenced by tacticity; the PVA showed a higher crystal melting temperature and higher modulus than those of commercial PVA. ${ }^{3}$ Hence we are interested in the synthesis of highly syndiotactic PVA through the radical polymerization of vinyl esters.

One way to obtain highly syndiotactic polymer is to use a suitable solvent. Some studies on solvent effects on tacticity of poly(vinyl ester)s have been published. Very small effects on the tacticity of poly(vinyl acetate) have been reported in usual solvents by Yamamoto et al., ${ }^{4}$ but Imai et al. reported a proton-donor solvent as phenol to give more syndiotactic polymer. ${ }^{5}$ Matsuzawa et al. investigated solvent effects on the tacticity of poly(vinyl trifluoro acetate) (PVTFA) and reported the solubility of PVTFA in the solvent to be important. ${ }^{6}$ Nozakura et al. reported solvent effects on the tacticity of poly(vinyl ester)s with various substituents including PVP and PVTFA. ${ }^{7}$ We also studied solvent effects on the tacticity of PVP to obtain highly syndiotactic PVA.

Vinyl pivalate (VP), $\alpha, \alpha^{\prime}$-azobisisobutyronitrile (AIBN) and solvents purified by the usual method were placed in a Pyrex tube. The mixture was degassed to repeat freezingpumping-thawing cycle, and sealed under vacuum. The tube was fixed in a thermostat bath and the mixture was irradiated with a high pressure mercury lamp. The polymer was precipitated in methanol or methanol/water, filtrated, reprecipitated and dried under vacuum. The degree of polymerization $\left(P_{n}\right)$ was determined from intrinsic viscosity in acetone at $25^{\circ} \mathrm{C}$.

The tacticity of PVA could be easily determined with ${ }^{1} \mathrm{H} \mathrm{NMR}$, and thus PVP was converted to PVA as follows: $200 \mathrm{ml}$ of $1 \%$ PVP-tetrahydrofuran (THF) solution were added to $20 \mathrm{ml}$ of $25 \% \mathrm{KOH}$-methanol solution and the mixture was stirred for $2 \mathrm{~h}$ at $40^{\circ} \mathrm{C}$ to yield PVA. The reaction was carried out under nitrogen. The resulting PVA was filtrated, washed with methanol and dried under vacuum at $60^{\circ} \mathrm{C}$. Triad tacticity was determined from the peak intensity of hydroxyl proton in the ${ }^{1} \mathrm{H}$ NMR spectrum of PVA measured with JEOL JNM EX-270.

Table I summarizes monomer conversion and $P_{n}$ of PVP obtained in various solvents at 
$20^{\circ} \mathrm{C}$. By $10 \mathrm{~h}$ irradiation, PVPs were obtained in high conversion in any solvents except benzene. The low conversion in benzene was considered caused by lowered reactivity of the propagating radical by $\pi$-complex formation with benzene as observed in the radical polymerization of vinyl acetate. ${ }^{8-10} P_{n} \mathrm{~s}$ of PVPs obtained in these solvents except dimethyl sulfoxide (DMSO) were not so high possibly due to frequent chain transfer reaction

Table I. Results of photo-polymerization of vinyl pivalate in various solvents ${ }^{\mathbf{a}}$

\begin{tabular}{lcr}
\hline \multirow{2}{*}{ Solvent } & \multicolumn{2}{c}{ Conversion } \\
\cline { 2 - 2 } & \multicolumn{1}{c}{$\%$} & $P_{n}$ \\
\hline Benzene & 4.6 & 900 \\
EtOH & 90.3 & 940 \\
Cyclohexane & 86.9 & 1760 \\
MeOH & 67.5 & 1900 \\
$n$-Hexane & 60.2 & 4720 \\
DMSO & 89.8 & 32000
\end{tabular}

${ }^{\text {a }}$ Polymerization temperature, $20^{\circ} \mathrm{C}$; polymerization time, $10 \mathrm{~h}$; monomer: solvent $=1: 1(\mathrm{v} / \mathrm{v}) ;$ [AIBN], $0.038 \mathrm{~mol} \%$ for monomer. in solvents. The reason for very high $P_{n}$ (ca. 30000) in DMSO is not clear but we consider that the chain transfer constant is not so large and/or the termination reaction is prevented by precipitation (trapping) of propagating radical because DMSO is poor solvent for PVP. The conversion is very high; thus the chain transfer reaction to polymer should be taken into account. However, as the other solvents in which high conversions were observed did not afford PVP of high $P_{n}$, we consider it not so important. Although the reason is not clear, the polymerization of VP in DMSO is important in industry.

The triad tacticity of PVP was determined from the ${ }^{1} \mathrm{H}$ NMR spectrum of corresponding PVA and diad syndiotacticity was derived from triad tacticity. Some of the results are listed in Table II. The diad syndiotacticity for PVPs obtained in various solvents at varying monomer (solvent) concentration is plotted against solvent concentration ( $\mathrm{vol} \%$ ) in Figure 1. As shown in Figure 1, the plots show a linear relation except in acetone, and the lines corresponded to (1) alkanes, alcohols, benzene

Table II. Tacticity of PVPs prepared in various solvents at $-20^{\circ} \mathrm{C}^{\mathrm{a}}$

\begin{tabular}{|c|c|c|c|c|c|c|c|}
\hline \multirow{2}{*}{ Solvent } & \multirow{2}{*}{$\begin{array}{l}\text { Dielectric } \\
\text { constant }\end{array}$} & \multirow{2}{*}{$\begin{array}{l}\text { Solubility } \\
\text { of } \mathrm{PVP}^{\mathrm{b}}\end{array}$} & \multicolumn{3}{|c|}{$\operatorname{Triad} / \%^{\mathrm{c}}$} & \multicolumn{2}{|c|}{$\operatorname{Diad} / \%^{\mathrm{d}}$} \\
\hline & & & $I$ & $H$ & $S$ & $i$ & $s$ \\
\hline$n$-Undecane & 2.01 & S & 9.9 & 48.0 & 42.1 & 33.9 & 66.1 \\
\hline$n$-Octane & 1.95 & $\mathrm{~S}$ & 10.2 & 46.8 & 43.0 & 33.6 & 66.4 \\
\hline$n$-Hexane & 1.89 & $\mathrm{~S}$ & 10.4 & 47.0 & 42.6 & 33.9 & 66.1 \\
\hline 2,2-Dimethylbutane $\mathrm{e}^{\mathrm{e}}$ & 1.87 & $\mathrm{~S}$ & 10.7 & 47.3 & 42.0 & 34.3 & 65.7 \\
\hline $\mathrm{MeOH}$ & 32.6 & LS & 10.3 & 47.4 & 42.3 & 34.0 & 66.0 \\
\hline$n$-Hexanol & 13.3 & $\mathrm{~S}$ & 10.7 & 47.6 & 41.7 & 34.5 & 65.5 \\
\hline $\mathrm{EtOH}$ & 24.6 & $\mathrm{~S}$ & 11.0 & 47.7 & 41.3 & 34.8 & 65.2 \\
\hline Benzene & 2.28 & $\mathrm{~S}$ & 10.9 & 48.3 & 40.8 & 35.0 & 65.0 \\
\hline Cyclohexane & 2.02 & $\mathrm{~S}$ & 11.2 & 48.2 & 40.6 & 35.3 & 64.7 \\
\hline Methyl acetate & 6.68 & $\mathrm{~S}$ & 11.4 & 49.6 & 39.0 & 36.2 & 63.8 \\
\hline Vinyl pivalate(monomer) & 4.70 & $\mathrm{~S}$ & 11.5 & 49.1 & 39.4 & 36.1 & 63.9 \\
\hline Methyl isobutyl ketone & 13.1 & $\mathrm{~S}$ & 11.7 & 49.4 & 38.9 & 36.4 & 63.6 \\
\hline Acetonitrile & 37.5 & I & 12.1 & 50.3 & 37.6 & 37.3 & 62.7 \\
\hline Acetone & 20.7 & $\mathrm{~S}$ & 12.6 & 49.9 & 37.5 & 37.6 & 62.4 \\
\hline Propylene carbonate & 69.0 & I & 12.9 & 49.4 & 37.8 & 37.5 & 62.5 \\
\hline $\mathrm{DMSO}^{\mathrm{f}}$ & 46.7 & I & 13.8 & 50.9 & 35.3 & 39.2 & 60.8 \\
\hline
\end{tabular}

${ }^{\mathrm{a}}$ Monomer : Solvent $=1: 1(\mathrm{v} / \mathrm{v}) .{ }^{\mathrm{b}} \mathrm{S}$, soluble; LS, less soluble; $\mathrm{I}$, insoluble. ${ }^{\mathrm{c}}$ Determined from ${ }^{1} \mathrm{H}$ NMR spectrum.

${ }^{\mathrm{d}}$ Determined from the values of triad. ${ }^{\mathrm{e}}$ Monomer : solvent $=3: 2(\mathrm{v} / \mathrm{v}) .{ }^{\mathrm{f}}$ Polymerization temperature, $20^{\circ} \mathrm{C}$. 


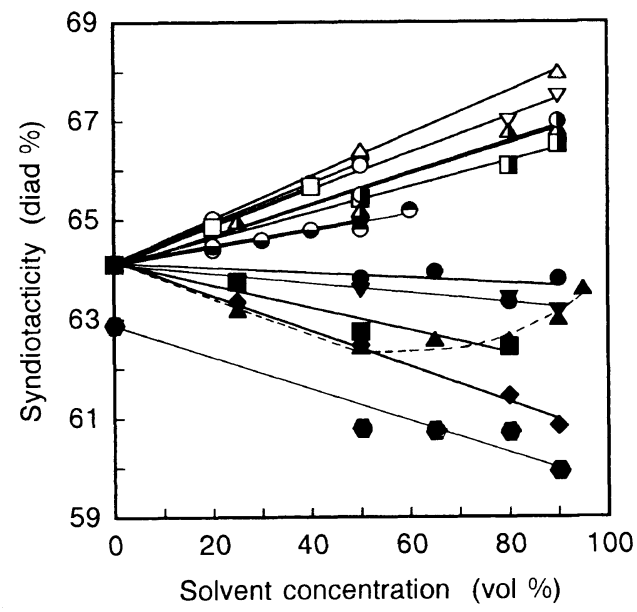

Figure 1. Plots of syndiotacticity of polymers vs. solvent concentration in the polymerization of vinyl pivalate at $-20^{\circ} \mathrm{C}: \square$, 2,2-dimethylbutane; $\nabla, n$-hexane; $\Delta, n$ octane; $\bigcirc, n$-undecane; $\Theta$, cyclohexane; $\Theta$, benzene; $\square$, $\mathrm{MeOH} ; \boldsymbol{\Lambda}$, EtOH; $\boldsymbol{\top}, n$-hexanol; $\bigcirc$, methyl acetate; $\boldsymbol{\nabla}$, methyl isobutyl ketone; $\boldsymbol{\Delta}$, acetone; $\boldsymbol{\square}$, acetonitrile; $\boldsymbol{\square}$, propylene carbonate; $\mathrm{DMSO}$ (polymerization temperature, $20^{\circ} \mathrm{C}$ ).

or cyclohexane, or (2) ketones or esters. The former was shown to make the PVP syndiotactic, and the latter, PVP less syndiotactic.

We made a computer simulation of the cotacticity of copoly(vinyl ester)s, found penultimate effect in the case of vinyl ester with bulky substituent and propose the structures of the transition state as stretched and helical for $r r$ and $m m$ propagations, respectively. ${ }^{11} \mathrm{We}$ consider that, in the polymerization of VP, the solvents which stabilize the helical structure by solvation make PVP less syndiotactic, and solvents which do not stabilize, make PVP syndiotactic. In this study we could find no relation between solubility and tacticity as proposed by Matsuzawa et al. on PVTFA. We consider the reasons as follows: (1) the steric effect is important in the polymerization of VP but the coulombic effect which is effective in long distance is important in the polymerization of VTFA. (2) as PVP is highly syndiotactic, it is considered to have affinity for non-polar solvents which have affinity for stretched structures. A polar solvent has affinity for the helical structure. Polymer dissolution is much complicated. Hence, no simple relation between solubility and tacticity in the polymerization of VP was found.

As above mentioned, we obtained very high molecular weight PVP in DMSO and highly syndiotactic PVP in $n$-alkane.

\section{REFERENCES}

1. T. Yamamoto, S. Yoda, O. Sangen, R. Fukae, and M. Kamachi, Polym. J., 21, 1053 (1989).

2. T. Yamamoto, S. Yoda, H. Takase, T. Saso, O. Sangen, R. Fukae, M. Kamachi, and T. Sato, Polym. J., 23, 185 (1991).

3. R. Fukae, T. Yamamoto, O. Sangen, T. Saso, T. Kako, and M. Kamachi, Polym. J., 22, 636 (1990).

4. T. Yamamoto, T. Yamamoto, T. Minamizawa, and M. Hirota, Kobunshi Ronbunshu, 36, 557 (1979).

5. K. Imai, T. Shiomi, Y. Tezuka, T. Kawanishi, and T. Jin, J. Polym. Sci., Polym. Chem. Ed., 26, 1961 (1988).

6. S. Matsuzawa, K. Yamaura, H. Noguchi, and H. Hayashi, Makromol. Chem., 165, 217 (1973).

7. S. Nozakura, M. Sumi, M. Uoi, T. Okamoto, and S. Murahashi, J. Polym. Sci., Polym. Chem. Ed., 11, 279 (1973)

8. T. Yamamoto, T. Yamamoto, A. Mito, and M. Hirota, Nippon Kagaku Kaishi, 408 (1979).

9. T. Yamamoto, T. Yamamoto, J. Izukawa, and M. Hirota, Kobunshi Ronbunshu, 36, 625 (1979).

10. M. Kamachi, D. J. Liaw, and S. Nozakura, Polym. J., 11, 921 (1979).

11. T. Yamamoto, M. Hanatani, T. Matsumoto, O. Sangen, T. Isono, R. Fukae, and M. Kamachi, Polym. J., 26, 417 (1994). 